\title{
O Diálogo Intercultural Universalismo dos Direitos Humanos para Além do Relativismo Cultural
}

\section{Gabrielle Tesser Gugel}

Advogada. Mestre em Direito Público pela Unisinos. Bacharel em Direito pela Universidade de Caxias do Sul. Presidente da Associação Nacional dos Emigrados e Ex-emigrados das Américas e Austrália - Brasil. gabitgugel@gmail.com

Os Direitos Humanos são uma janela através da qual uma cultura determinada concebe uma ordem humana justa para seus indivíduos, mas os que vivem naquela cultura não enxergam a janela; para isso, precisam da ajuda de outra cultura, que, por sua vez, enxerga através de outra janela. Eu creio que a paisagem humana vista através de uma janela é, a um só tempo, semelhante e diferente da visão de outra. Se for este o caso, deveríamos estilhaçar a janela e transformar os diversos portais em uma única abertura, com o consequente risco de colapso estrutural, ou deveríamos antes ampliar os pontos de vista tanto quanto possível e, acima de tudo, tornar as pessoas cientes de que existe, e deve existir, uma pluralidade de janelas? A última opção favoreceria um pluralismo saudável (Panikkar, 2004). 


\title{
Resumo:
}

0 tema do presente texto é uma reflexão sobre o multiculturalismo e o relativismo cultural, bem como se a concepção dos direitos humanos é ocidental. Para isso, inicia-se descrevendo as principais correntes relativistas e noções antropológicas acerca do multiculturalismo. 0 objetivo do estudo propõe-se a demonstrar que 0 universalismo dos direitos humanos precisa diferenciar as noções de universal, uniforme e comum, visto que esses dois, erroneamente, são confundidos com o universal. A metodologia aplicada será desenvolvida a partir do método sistêmico construtivista, cuja pesquisa tem por base uma perspectiva transdisciplinar. A complexidade de tal tema envolve diversas matérias, não somente jurídicas, mas também relacionadas à história e à sociologia. Os resultados presentes das pesquisas foram satisfatórios, uma vez que a pesquisa bibliográfica realizada demonstrou que 0 tema gera discussões. Dessa forma, como os direitos humanos geram discussões acerca de sua fundamentação, concluiu-se que é necessário demonstrar que eles são construção histórica, cuja noção perpassa aquela descrita da Declaração Universal dos Direitos Humanos, bem como que, apesar de sua preponderante noção ocidental, são muito mais profundos e por isso passíveis de universalidade.

Palavras-chave: Universalismo. Multiculturalismo. Relativismo cultural.

\section{THE INTERCULTURAL DIALOGUE: UNIVERSALISM HUMAN RIGHTS BEYOND THE CULTURAL RELATIVISM}

\begin{abstract}
:
The theme of this text is a reflection on multiculturalism and cultural relativism and if the concept of human rights is Western. For this, starts describing the main current relativistic and anthropological notions of multiculturalism. The aim of the study aims to demonstrate the universality of human rights need to differentiate universal notion of uniform and common, that erroneously are confused with the universal. The methodology will be developed from the constructivist systemic method, whose research is based on an interdisciplinary perspective. The complexity of this issue involves different subjects, not only legal, but also related to the history and sociology. The present results of the research were satisfactory, since the bibliographical survey showed that the topic generates discussions. So, as human rights generate discussions about its foundation, it was concluded that it is shown that they are historical construction whose notion permeates one described the Universal Declaration of Human Rights, and that, despite its predominant Western notion, are much deeper and therefore subject to universality.
\end{abstract}

Keywords: Universalism. Multiculturalism. Cultural relativism.

\section{Sumário:}

1 Introdução. 2 Multiculturalismo e Relativismo Cultural: reflexão intercultural. 30 universalismo que perpassa as noções do uniforme e comum. 4 Direitos humanos universais como construção histórica humana ou concepção ocidental? 5 Considerações finais. 6 Referências. 


\section{INTRODUÇÃO}

O presente texto tem por escopo apresentar uma reflexão acerca da concepção universal dos direitos humanos. Ora, ela é possível? Os discursos realizados por multiculturalistas e relativistas culturais tendem a rejeitar a ideia de universalismo dos direitos humanos por entenderem que tal concepção não seria possível, justamente em virtude das diferenças entre as culturas.

Para isso, inicialmente contextualiza-se as noções defendidas pelo multiculturalismo e relativismo cultural, trazendo-se a política do reconhecimento como forma de buscar a identidade de cada cultura. Além do multiculturalismo, o próprio pluralismo cultural demonstra que as culturas, no seu ordenamento interno, apresentam impasses culturais, pois são influenciadas por culturas externas, bem como forças internas que divergem daquela considerada oficial. Mesmo que as culturas sejam diferentes, será que tal diferença é realmente tão grande como parece? Para esclarecer tal questão apresentam-se as ideias de James Rachels acerca das diferenças entre os sistemas de crenças de cada cultura.

Busca-se, então, explicar o que seria o universal dos direitos humanos. Para tanto, a base teórica dar-se-á com o livro do escritor François Jullien, uma vez que este consegue abarcar as complexidades que envolvem a noção do universal, bem como diferenciá-lo de duas ideias com as quais é comumente confundido, quais sejam, a de uniformidade e a de comum. Apresenta-se que a uniformidade ocasiona a homogeneização de culturas, posto que impõe os padrões culturais de uma cultura em detrimento das demais, sem que aquelas prejudicadas percebam que estão sendo influenciadas e perdendo-se no tempo. Tal homogeneização é impulsionada pela globalização. Ainda, demonstra-se que o universal não promove a padronização, ao contrário, preserva o individual, as diferentes culturas. 
Por fim, apresenta-se a discussão se os direitos humanos universais são uma construção histórica humana ou uma concepção ocidental, visto que, desde a sua formulação, o Ocidente tende a impor a sua cultura sobre os países orientais. Nesse sentido, analisa-se a importância histórica da Declaração Universal dos Direitos Humanos, bem como até que ponto os direitos ali descritos são universais e qual a legitimidade de os países do mundo pan-europeu intitularem-se os responsáveis para "levar" direitos humanos e democracia aos demais Estados. Além disso, apresenta-se a ideia de universalismo universal construída por Wallerstein, tendo em vista que, para ele, a concepção de direitos humanos que hoje é defendida promove o pensamento europeu; dessa forma, o universalismo universal promoveria o diálogo intercultural.

\section{MULTICULTURALISMO E RELATIVISMO CULTURAL: REFLEXÃO INTERCULTURAL}

Para que se possa adentar no campo do multiculturalismo, antes de tudo é preciso abordar acerca da política do reconhecimento. A partir do século 18, o pensamento filosófico passou a mostrar que o reconhecimento está intimamente ligado à noção de identidade; melhor dizendo, o modo de cada ser humano sentir-se como tal, enquanto ser integrante de determinada cultura. Com a perspectiva do reconhecimento, observa-se que as pessoas podem reconhecer ou não a identidade de outro grupo, julgá-lo correto ou incorreto. Ocorre que, por exemplo, quando um grupo dominador julga incorreto o sistema de crenças e a dignidade do grupo dominado, não os respeita, enquanto o grupo dominado, ao ser depreciado, altera o julgamento sobre si mesmo, passa a sentir-se, consequentemente, inferior (deixa de acreditar na sua própria dignidade) e, por conseguinte, subjuga-se ou revolta-se contra aquele (Taylor, 1998, p. 45-46).

Para uma política do reconhecimento do ser humano, a partir da noção de identidade que perpassa as diferentes culturas, necessita-se esclarecer que existem capacidades humanas que são inerentes a essa 
condição (humana), independente da cultura. Ou seja, todo o ser humano possui "capacidade de pensar, raciocinar, utilizar a linguagem para comunicar-se, de escolher, de julgar, de sonhar, de imaginar, de imaginar projetos de uma vida plena, e de estabelecer relações com os seus semelhantes, pautadas em critérios morais”. Todas essas particularidades fazem parte do ser humano e o distinguem dos demais seres vivos e, por isso, ao serem comuns, pode-se afirmar que o ser humano pertence a uma comunidade universal. É evidente que em cada cultura as características suprarreferidas terão uma forma de tratamento diferenciada, contudo, não deixam de identificar o ser humano em si. Pode-se referir que isso forma o se denomina identidade humana (Barreto, 2010, p. 249-251). Como se observa, o conhecimento da identidade é importante para o ser humano, e, por isso, envolve esses diferentes graus de percepção, pois a identidade pode referir-se a uma característica que qualifica o ser humano como tal dentro de uma cultura, mas também pode identificá-lo como ser humano dentro da comunidade humana, atribuindo-lhe uma identidade universal.

Desse modo, Taylor (1998, p. 57-58) observa dois níveis para o discurso do reconhecimento. O primeiro seria o nível individual, de uma pessoa reconhecer a sua identidade como um ser que faz parte e interage com a sociedade. $\mathrm{O}$ segundo diz respeito a uma política do reconhecimento, no âmbito do poder público, a qual se fundamentou na concepção de proteção da dignidade para todos os cidadãos. Há certo caráter de universalidade intrínseco a essa política de reconhecimento porque, a partir do momento em que se reconhece a dignidade como direito humano de todos os seres, não se justificam atos do poder público que desprezem ou depreciem outras culturas; aliás, seu sistema de crenças sequer poderia ser considerado inferior/superior ao das demais. Para o autor, essa política está relacionada à proteção da diferença, com consequente manutenção do multiculturalismo, ou seja, a política do reconhecimento iguala quando diferencia. 
Uma leitura redutora do multiculturalismo dá a entender que a corrente relativista negaria a concepção universal dos direitos humanos. Isso ocorre porque se forma a ideia de que existiriam diferentes valores, crenças, costumes, em cada uma das culturas, logo, não seria possível assegurar o bem viver de forma igualitária para todos os seres humanos. Independente da cultura de cada povo, porém, é importante observar que existem necessidades que são iguais em todas as culturas, haja vista que a natureza humana impera e identifica os outros como seus semelhantes (Barreto, 2010, p. 239-240). Afinal, os seres humanos pertencem à comunidade humana. $\mathrm{O}$ que pode ser diferente é o sistema de crenças, ou seja, o modo como determinado fato é valorizado pela comunidade. ${ }^{1}$

Dentro do pensamento filosófico encontram-se três correntes relativistas que rechaçam a perspectiva dos direitos humanos universais. Seriam elas o relativismo antropológico, o relativismo epistemológico e o relativismo cultural. $\mathrm{O}$ relativismo antropológico aporta-se na ideia de que a sociedade é multicultural, cujos códigos morais e jurídicos são diferentes, por isso não há como se prescrever um conjunto de valores e regras que sejam universais. Apesar dessa justificativa antropológica, é importante observar que, mesmo com o pluralismo cultural, existem necessidades humanas que são comuns em todas as culturas, como o sentimento de afeição, a necessidade de reconhecimento, de cooperação, a compaixão;

${ }^{1}$ Para entender melhor essa afirmação, traz-se o exemplo de James Rachels (2006, p. 23-24) ao apontar que as culturas não são tão diferentes quanto parecem: "considere uma cultura na qual as pessoas acreditam que é errado comer carne de vaca. Esta pode até ser uma cultura pobre, em que não há comida suficiente; mesmo assim, as vacas não serão tocadas. Uma sociedade como esta parece possuir valores muito diferentes dos nossos. Mas será que realmente possui? Não perguntamos ainda o porquê de não comerem carne de vaca. Suponha que haja uma crença de que após a morte as almas das pessoas habitem os corpos dos animais, especialmente os das vacas; assim, uma vaca pode ser a avó de alguém. Agora, devemos dizer que seus valores são diferentes dos nossos? Não, a diferença não está aí. A diferença está no nosso sistema de crenças, não em nossos valores. Concordamos com o fato de que não devemos comer a carne de nossa avó e simplesmente discordamos sobre o fato de que a vaca é (ou poderia ser) nossa avó”. 
logo, tais necessidades seriam universais. O pluralismo cultural revela que as próprias culturas/sociedades têm posições conflitantes em relação aos preceitos religiosos e culturais considerados oficiais no seu ordenamento interno. Isso porque as culturas não são sistemas fechados, muito antes, pelo contrário, são influenciáveis, tanto por fatores externos (outras culturas), quanto internos (forças sociais divergentes da oficial). Por isso, nessa perspectiva antropológica, além do multiculturalismo, o pluralismo cultural observa que todas as culturas são pluralistas, apresentado diversas interpretações às práticas culturais. O relativismo epistemológico propõe que dentro dessa perspectiva de multiculturalismo não é possível formular um discurso ético que perpasse todas as culturas. Por fim, o relativismo cultural determina que as características que diferenciam uma cultura de outra são fundamentais para assegurar o modo com que os valores serão protegidos pelos direitos humanos (Barreto, 2010, p. 240-241).

Especialmente no campo da antropologia é possível observar e compreender o comportamento de cada cultura, dentro de cada contexto social e comunitário; por isso as concepções de correto e incorreto não são as mesmas em todas as culturas, inclusive para James Rachels (2006, p. 17-18): "se assumirmos que nossas idéias éticas serão compartilhadas por todas as pessoas em todos os tempos, estaremos sendo ingênuos”. É justamente por isso que a postura ética diante do relativismo cultural demanda analisar detalhadamente os costumes, sistema de crenças e a moralidade de cada cultura, bem como se tal moralidade pode ser considerada objetivamente plausível. Não se pode ser ingênuo diante do relativismo cultural, pois é fato que ele existe; basta observar os diversos sistemas de crenças e culturas que estão presentes em cada cultura, porém, a necessidade de respeito impera.

Além das diferenças entre as noções de certo/errado, observa-se que diferentes culturas podem não ver nos direitos humanos uma concepção suficiente para o viver em sociedade. Raimundo Panikkar explica isso 
ao apresentar a visão indiana - compreensões tradicionais hindu jairusta e budista de realidade -, não para formular um equivalente homeomórfico aos direitos humanos, mas, sim, para tentar construir um terreno comum entre dois sistemas de crença diversos. O darma é a palavra indiana que tem várias significações, como "elemento, dados, qualidade e surgimento, ela significa lei, norma de conduta, o caráter das coisas, direito, verdade, ritual, moralidade, justiça, retidão, religião, destino e muitas outras coisas”, vê-se que não é possível encontrar uma única palavra em língua ocidental que faça a devida correspondência com ele. Por isso "o Darma é aquilo que mantém e dá coesão e portanto força, a qualquer coisa dada, à realidade, e, em última análise, aos três mundos (tnloka)”, como um todo. Como o darma é fundamental na cultura indiana, observa-se que ele não pode ser reduzido à categoria moral, haja vista que "engloba conflito e solução; o que se deve e o que não se deve. Não há Darma universal acima e independente do svadharma, o Darma inerente a cada ser. E este svadharma é, a um só tempo, resultado da reação ao Darma de todos os outros”. Então, para o autor, o correspondente homeomórfico aos direitos humanos seria o svadharma, mas não quer dizer que a concepção de direitos humanos abarque tudo o que a expressão indiana significa, porém, para que se mantenha a ordem dármica, na cultura indiana há o svadharma, enquanto na ocidental, para manter uma sociedade justa, há os direitos humanos (Panikkar, 2004, p. 230-232).

Apesar de o relativismo cultural, portanto, como teoria da moralidade, implicar que quando as pessoas assumem as diferenças culturais não poderiam avaliar se determinada cultura é evolutiva ou eticamente inferior a sua própria, afinal, como o correto e o incorreto são relativos, tal julgamento feriria o multiculturalismo e igualaria culturas que não são iguais; uma postura crítica não pode ser esquecida. Tal postura faz com que se deixem de lado as noções de progresso e superação de práticas condenáveis, alterações legislativas que, ao longo dos anos, seguiram nada mais que o curso social (Rachels, 2006, p. 22-23). Logo, o respeito por 
outra cultura não demanda que o relativismo cultural seja visto como algo impermeável ou acrítico, pois é fato que o relativismo existe, mas não quer dizer que não possa coexistir a concepção universal de direitos humanos.

\section{O UNIVERSALISMO QUE PERPASSA AS NOÇÕES DO UNIFORME E DO COMUM}

No item anterior analisou-se sobre a relação entre o multiculturalismo e o relativismo cultural, procurando desmistificar a ideia de que este seria incompatível com a noção universal dos direitos humanos. Resta neste tópico explicar como identificar o universal, diferenciando-o das concepções do uniforme e do comum, tendo em vista que, muitas vezes, estas são confundidas com ele.

O universal é um conceito racional, e provém do pensamento grego como uma forma de ver a realidade, ou seja, não é um simples conceito. $\mathrm{O}$ termo foi incorporado pela cultura ocidental, e hoje, conforme se observa, espalha-se por todas as culturas. Por vezes, é erroneamente interpretado e utilizado nos discursos que tentam homogeneizar as culturas, ou mesmo naqueles que expressam a democracia como parâmetro mundial de desenvolvimento e paz, e, para tanto, "levam-na" aos demais países (Marcondes,

2009 , p. 7-8). É por isso que, visando a captar o sentido que o termo universal abarca, François Jullien (2009) diferencia-o do conceito de uniforme e de comum.

Tendo em vista que a justificativa para o conceito do universal é racional, conforme supra-apontado, explica François Jullien que o termo apresenta dois níveis de universalidade: a universalidade fraca refere-se à adoção de costumes, prática social, por conveniência do uso comum, ou seja, um consenso que é apresentado como verdadeiro; já a universalidade forte seria aquela que é real, que não é determinada pela experiência, mas, sim, pelo dever-ser, de modo que determinado ato social é assim porque 
deve ser assim e não pode ocorrer de outra forma. Conforme se observa, no primeiro caso um costume pode tão somente estender-se a outras culturas, formando, então, um juízo geral, porém, no segundo caso, o fato é imperativo, ou seja, absoluto. Por isso, somente na universalidade forte é que se encontra o verdadeiro sentido do universal. Nesse caso, na Declaração Universal dos Direitos do Homem o termo universal refere-se a todos os Estados, logo, é de se admitir que apresenta universalidade forte, constituída pela necessidade de elaborarem-se os princípios dos direitos humanos. O documento internacional, ao declarar os direitos, cria a sua legitimidade e evoca um dever-ser (Jullien, 2009, p. 19-20, 22). O conceito proposto pelo autor é que o universal, diante do multiculturalismo, ultrapassa todas as diferenças existentes entre as culturas.

Independente dessas diferenças, James Rachels (2006, p. 26) observa que "existem algumas regras morais que todas as sociedades devem ter em comum, porque são necessárias para a existência da sociedade”. Ou seja, o autor explica que as regras contra o assassinato e a mentira estão presentes em todas as culturas, senão viver em sociedade seria inviável. O que muda em cada uma delas são as exceções consideradas legítimas quando da ocorrência de tais violações. Assim, as diferenças entre as culturas, na realidade, são superestimadas, pois não são todas as regras morais que mudam de uma cultura para outra, mas tão somente as exceções. A concepção do universal não deixa de atentar para essas diferenças individuais de cada cultura, lembrando que há normas que decretam os valores morais em todas as culturas, e tais valores estão presentes.

Na sociedade contemporânea observa-se que, ao contrário do universal evocado pela Declaração, o que o universal realmente busca é a proteção do singular, ou seja, da outra cultura local. Os direitos humanos até então foram impostos pelo imperialismo europeu, porém a sua manutenção ao texto europeu é uma contradição à própria ideia de universalidade dos direitos humanos (Jullien, 2009, p. 28). Por isso, Raimundo Panikkar 
(2004) questiona-se se o símbolo dos direitos humanos deve ser universal. Para essa pergunta, o autor apresenta duas respostas: a primeira é que sim, pois, quando uma cultura considera seus valores como elevados, estes passam a possuir um caráter de universal, uma vez que são valores expressos culturalmente. Logo, a Declaração Universal de Direitos Humanos deve ter uma eficácia universal. Se tais direitos não fossem considerados universais, seria como afirmar-se que não são humanos, e perderiam sua razão de ser. A importância da Declaração foi justamente reconhecer que todo ser humanos, pelo simples fato de sê-lo, tem o direito de que sua dignidade seja respeitada; a segunda resposta é que não, porque dentro da realidade de cada cultura os seus valores máximos não são universalizáveis, uma vez que pertencem a sua tradição e símbolos (Panikkar, 2004, p. 226-227).

A noção de universal, via de regra, é confundida com a de uniforme. Ocorre que este, ao contrário daquele, não busca proteger o multiculturalismo; na realidade o que faz é copiar uma cultura de outra, pois, "enquanto o universal é ‘voltado’ para o Um - uni-versus - e traduz uma aspiração a seu respeito, o uniforme não é. Desse $u m$, senão uma repetição estéril”. A uniformidade, ao longo dos anos, esteve presente em muitos dos discursos daqueles que "levam" os direitos humanos e democracia para outros países, ou seja, erroneamente o uniforme apresenta-se como universal. Carece ao uniforme, contudo, o caráter de dever-ser que o universal traz consigo, ou seja, aquilo que é introduzido em outra cultura, simplesmente por repetição; não possui o sentido que o universal apresenta. Desse modo, o uniforme é um padrão; não provém da necessidade de uma cultura, mas, sim, de um fator externo que introduz algo, o qual, posteriormente, é reproduzido pela sociedade, por isso se observam reproduções de códigos, valores, jurisdições. Ao contrário, o universal apresenta justamente a proteção do singular, do outro inalienável (Jullien, 2009, p. 29-30). 
Mediante a globalização a uniformização alcança novas fronteiras, pois é por meio dela que o uniforme propaga-se despercebido entre diferenças culturais, porém faz isso se passando por universal. Percebe-se que o uniforme impõe os seus modelos, sem parecer fazê-lo, considerando que não o faz por meio do direito, mas, sim, de diversas mídias, distribuições de livros pelo mundo, telejornais de todos os Estados que são controlados por grupo de notícias ocidental. Assim, ao tomar o universal como uniforme, encontramos uma das maiores barreiras no diálogo intercultural, mas também a sua utilidade, para criticar a universalidade distorcida que o mundo pan-europeu defende, pois "perdemos ao mesmo tempo o que constitui a ajuda - que não seja apenas preservadora ou museológica da diversidade das culturas; bem como o plano - que não seja apenas de imitação ou de assimilação - no qual elas poderiam se encontrar” (Jullien, 2009, p. 32-34).

Da mesma forma, para Boaventura de Souza Santos (2004, p. 246249), “a globalização é o processo pelo qual determinada condição ou entidade local estende a sua influência a todo o globo e, ao fazê-lo, desenvolve a capacidade de designar como local outra condição social ou entidade rival”. O autor define quatro processos de globalização, cuja importância reflete diante do multiculturalismo: localismo globalizado, ocorre quando um fenômeno local globaliza-se com sucesso, como as redes de fast food; globalismo localizado são impactos sofridos em razão de valores transnacionais introduzidos em uma cultura, que desestruturam as condições locais; cosmopolitismo são os movimentos que lutam contra as exclusões culturais e discriminações trazidas pelo localismo globalizado e globalismo localizado - seria uma espécie de solidariedade para preservação das culturas, diante da globalização; temas que envolvam o patrimônio comum da humanidade, seriam as questões que envolvem toda a humanidade e, por isso, precisam ser protegidas e respeitadas. Conforme se observa, esses dois últimos processos, referidos pelo autor, entram em conflito com os dois primeiros e são meios para impedir a uniformização. 
Além disso, outro impacto dessa imposição ocidental pode ser observado na homogeneização da educação, o que resulta na "negação das contribuições das civilizações não-ocidentais para a cultura humana e a alienação de suas novas gerações em relação a suas próprias sociedades e seus ambientes naturais”. Isso porque as percepções não ocidentais são marginalizadas, e o único paradigma válido é o ocidental. A História da humanidade é escrita como a História da Europa, sem considerar todas as culturas, ou seja, sem considerar o pluralismo. Aliás, esse é um dos fatores para que não se leve em conta a importância das outras culturas, posto que rompa com a sua contribuição para a História da humanidade (Davutoglu, 2004, p. 120-123).

De outro modo, o comum diferencia-se tanto do universal, por não ser derivado da lógica racional, quanto do uniforme, haja vista que não tem caráter de padronização. O comum é uma concepção essencialmente política, ou seja, da comunidade; seria o que determinada cultura compartilha e é seguido pelas pessoas que ali se encontram. É importante diferenciá-lo da ideia de semelhante, tendo em vista que este se atém somente às aparências, enquanto o comum é um conceito forte, que traça o que é verdadeiro e aceito culturalmente. Enquanto o universal é decretado, na forma do dever-ser, conforme explicado anteriormente, o comum é reconhecido e apoiado pela sociedade, e enraíza-se por meio da experiência. $\mathrm{O}$ indivíduo, enquanto pertencente a uma sociedade, já se acha imerso no comum, bem como deliberativamente, pelas escolhas feitas em comunidade, origina o comum (Jullien, 2009, p. 36-37).

Logo, mesmo que se queira que o comum seja elevado ao caráter de universalidade, quando é reconhecido por todos, é necessário observar que as noções de universal e comum possuem dois níveis opostos, ou seja, “de abstração do universal (como ser de pensamento) de um lado, e, de outro, de instanciação do comum, como exigência consumada no âmbito dos particulares”. Isso está presente, por exemplo, na Declaração Universal dos Direitos Humanos. Enquanto ela prescreve no seu preâmbulo que é universal e deve ser seguida por todos, somente a partir de sua experi- 
ência e participação efetiva é que ela tem sentido, e isso ocorre no âmbito do comum (Jullien, 2009, p. 38-39). Por isso, partindo dessa diferenciação entre as três concepções, a Declaração Universal pode ser considerada um texto político e, desse modo, comum, posto que compartilha o que a comunidade dos países que a ratificaram acredita fundamental para a proteção dos direitos humanos.

É importante observar que o comum, como traz a ideia de comunidade a partir do que é compartilhado por ela, ao mesmo tempo exclui aqueles que não fazem parte desse meio, logo, "ou se o comum tem como oposto não mais o individual ou o singular, mas sim o próprio ou o particular, veremos também que esse 'próprio', adverso, nem por isso deixa de ameaçar absorvê-lo; e por conseguinte de abalar completamente o seu ideal.” Por isso o comum, dependendo da sociedade, pode ser aberto às demais, permitindo a sua comunicação com elas, bem como a circulação. Por outro lado, pode manter-se fechado, e impor barreiras às outras culturas, não permitindo a participação dos demais, isso ocasiona o movimento do comunitarismo, presente na sociedade contemporânea (Jullien, 2009, p. 42).

Dessa forma, François Jullien foi bem-feliz na distinção que fez entre a concepção universal, uniforme e comum, pois possibilita uma análise mais profunda do universalismo dos direitos humanos. É fundamental que se perceba que o universal não promove a padronização; ao contrário preserva o individual, as diferentes culturas. No mais, é importante que se estabeleça a importância política da Declaração Universal dos Direitos Humanos, por caracterizar o pensamento comum dos países que a ratificaram.

\section{DIREITOS HUMANOS UNIVERSAIS COMO CONSTRUÇÃO HISTÓRICA HUMANA OU CONCENPÇÃO OCIDENTAL?}

A teoria sobre a universalidade dos direitos humanos não é bem-aceita pelos adeptos da visão reducionista trazida pelo relativismo cultural. No contexto do multiculturalismo, contudo, para que os direitos humanos 
justamente não violem os direitos de outras culturas, precisam ser percebidos como construção histórica, e não como manifestação abstrata, ditada unilateralmente por determinada cultura. Por isso, a teoria que se formula sobre os direitos humanos deve observar as particularidades das outras culturas. Tal teoria apresenta dois tipos de análise: a primeira seria jurídica, visando à apreciação de todo o conjunto de tratados internacionais e dos mecanismos que garantam a efetivação dos direitos fundamentais no plano nacional e internacional; a segunda análise diz respeito ao fundamento dos direitos humanos, tanto na perspectiva filosófica quanto política. Ambos os níveis de reflexão são importantes, pois somente será possível a sua eficácia se os Estados possuírem mecanismos para sua promoção, além do que é preciso que estes direitos sejam reconhecidos pela sociedade (Barreto, 2010, p. 235-236). É por isso que toda a discussão sobre o multiculturalismo encontra certos empecilhos quando do reconhecimento da Declaração Universal dos Direitos Humanos, de 1948, e necessita-se que se explore melhor essa construção histórica dos direitos humanos.

Muitos são os documentos internacionais que, ao longo dos anos, foram construindo a noção dos direitos humanos, como a Magna Carta de 1215, a Lei de Habeas Corpus inglesa de 1679, a Declaração de Direitos (Bill of rights) inglesa de 1689 e as Declarações de Direitos da Revolução Francesa, ${ }^{2}$ porém é inegável que a Declaração Universal dos Direitos Humanos de 1948, originada do período pós-Segunda Guerra Mundial, constitui-se de uma força ímpar na defesa dos direitos humanos, bem como fomenta as discussões acerca do universalismo dos direitos humanos, pois o seu próprio nome já a intitula a um caráter universal. Para

${ }^{2}$ Para aprofundar o estudo acerca desses documentos internacionais, consultar a obra: Comparato, Fábio Konder. A afirmação histórica dos direitos humanos. 5. ed. rev. e atual. São Paulo: Saraiva, 2007. 
Douzinas (2009, p. 130), os "tratados e códigos de direitos humanos são um novo tipo de lei positiva, o último e mais seguro abrigo de um positivismo sui generis”.

O preâmbulo da Declaração Universal dos Direitos Humanos revela que esta foi redigida sob o impacto das atrocidades ocorridas durante a Segunda Guerra Mundial. Apesar de ter sido aprovada por unanimidade, nem todos os membros das Nações Unidas concordavam com os termos do Tratado; logo, abstiveram-se de votar os países comunistas - União Soviética, Ucrânia e Rússia Branca, Tchecoslováquia, Polônia e Iugoslávia -, a Arábia Saudita e a África do Sul. Segundo a Carta das Nações Unidas, no seu artigo $10^{\circ}$, a Declaração Universal seria uma recomendação aos estados membros das Nações Unidas. De qualquer modo, no contexto contemporâneo reconhece-se a vigência dos direitos humanos que ali estão contemplados, sem que haja a necessidade de que sejam transcritos no ordenamento interno dos Estados signatários, ou seja, a proteção da dignidade humana não depende da declaração de tal direito na constituição interna, porque já é reconhecido como direito humano (Comparato, 2007, p. 226-227).

Os autores da Declaração Universal recusavam que houvesse um consenso acerca da universalidade do conjunto de direitos humanos garantidos, se os Estados não os contemplassem no seu texto constitucional nacional, por isso firmaram o consenso de que a Declaração deveria prescrever os mecanismos de garantia, haja vista que a concordância entre as diferentes culturas e sistemas de crenças não seria possível, ou seja, somente seriam considerados direitos quando incorporados no sistema jurídico nacional. Após a Declaração Universal, outros tratados foram firmados para a proteção dos direitos humanos, ampliando a gama desses direitos, porém muitas violações seguem ocorrendo, por isso a discussão acerca da universalidade é tão importante (Barreto, 2010, p. 236-237). A par disso, é fundamental observar que o preâmbulo da Declaração Uni- 
versal expressa que os indivíduos devem esforçar-se para assegurar o seu reconhecimento e sua observância universais e efetivos, tanto entre os povos dos próprios estados membros quanto entre os povos dos territórios sob sua jurisdição.

Por isso, ressalta-se a importância da Declaração Universal quando se trata da observância dos direitos humanos. Anteriormente falou-se sobre as duas análises possíveis para a teoria dos direitos. Em um plano está a questão da fundamentação desses direitos, e, no outro, os mecanismos para sua garantia a proteção. A fundamentação dos direitos humanos é consequência da doutrina positivista que prevalece na sociedade contemporânea e direciona ao pífio apego aos conceitos previamente definidos, tendo em vista que buscar uma fundamentação além dessa racionalidade não possui prática jurídica. Essa noção fragiliza a proteção dos direitos humanos, porque muitos Estados não são signatários ao Tratado, e, mesmo aqueles que o são, violam os direitos. Logo, a necessidade de uma fundamentação é uma forma de proteger a aplicação do direito cogente do Estado, além de ser um reflexo democrático positivista, ou seja, uma forma de garantir a democracia. Com a Declaração Universal pensou-se que o problema da fundamentação dos direitos humanos estava resolvido; contudo observa-se que os mesmos não são, muitas vezes, reconhecidos, e a Declaração não foi ratificada por todos os Estados do mundo. Logo, o que se busca é uma fundamentação metajurídica que justifique a sua universalidade, mas que também os afirme como princípios gerais do direito (Barreto, 2010, p. 247-248).

Para Norberto Bobbio (2004, p. 25-26), na sociedade contemporânea os diretos humanos não encontram problemas na sua justificação em razão da Declaração Universal e demais tratados acerca do tema, mas, sim, na sua proteção. Melhor dizendo, não se necessita procurar qual é o seu fundamento, a sua origem, se é direito natural ou histórico; o que precisa ocorrer é impedir que não sejam respeitados. Sobre o problema 
do fundamento dos direitos humanos, o autor entende que já foi resolvido com a aprovação da Declaração Universal dos Direitos Humanos, isso porque com a Declaração há um "consenso geral acerca da sua validade”.

Não é possível, entretanto, concordar com a visão de Norberto Bobbio, pois, mesmo que os direitos humanos não tenham um fundamento absoluto (conceito trazido por Kant), porque são direitos históricos, isso não muda a possibilidade de que se questione o porquê de esses direitos existirem. Bobbio não enxerga uma relação entre a construção fática e a construção discursiva de verdade, ou entre a teoria e a prática, pois, como eles são históricos, têm um fundamento, uma razão de ser. O limite da positivação é uma razão de ser do mundo, e os cidadãos precisam entender o que querem dizer. Além disso, a ideia do autor acerca da desnecessidade de fundamentação, pois esse problema já teria sido resolvido com a Declaração Universal, não se coaduna com as discussões atuais, tendo em vista que os problemas apontados pelo multiculturalismo demonstram que a fundamentação dos direitos humanos está sem resolução; não tanto na "listagem” desses direitos humanos, mas na razão de ser. Por isso, eleger um fundamento absoluto é justamente o que é contestado pelas outras culturas. Esses direitos precisam de boas razões, assim como necessitam de fundamentação. Nada se afirma sem fundamentação.

Conforme se observa, os direitos humanos, enquanto construção histórica, geram discussões sobre a sua fundamentação. Com a Declaração Universal dos Direitos do Homem e sua consequente ratificação pelos países pertencentes às Nações Unidas, passou-se a questionar se tais direitos não seriam ocidentais ao invés de universais, conforme declarado no referido Tratado Internacional.

Para explicar essa situação, Wallerstein (2007, p. 26-27) explica que no ocidente, especialmente na Europa e países americanos, o universalismo tem sido levantado como justificação para as políticas desses países 
sobre aqueles não considerados desenvolvidos; ${ }^{3}$ nesse caso fala-se em propagação de valores universais. $\mathrm{O}$ autor destaca que os líderes apelam para três justificativas para defender o universalismo: a política seguida pelos líderes do mundo pan-europeu promove os direitos humanos e a democracia; apesar do multiculturalismo, a civilização ocidental é considerada superior às demais, bem como detentora das verdades universais, tanto que firmou uma Declaração que se intitula Universal; e a última leva em consideração a condição econômica, no sentido de que não há como agir senão de acordo com a modelo neoliberal. Por isso, Wallerstein (2007) chama o universalismo defendido pelo mundo pan-europeu como universalismo europeu, pois, apesar da fachada bonita que ele aparenta, não passa

${ }^{3}$ Nos discursos de George W. Bush para justificar a invasão no Afeganistão e Iraque, ele refere que a missão da América seria levar a democracia (utilizada claramente como um conceito universal) a esses países, por isso seguem alguns trechos dos seus discursos: "History has called America and our allies to action, and it is both our responsibility and our privilege to fight freedom's fight. (...) And we have a great opportunity during this time of war to lead the world toward the values that will bring lasting peace (George W. Bush, State of the Union, 2002)"; "History has called our Nation into action. History has placed a great challenge before us: Will America, with our unique position and power, blink in the face of terror, or will we lead to a freer, more civilized world? There's only one answer: This great country will lead the world to safety, security, peace, and freedom (George W. Bush, Address to the Nation on the Proposed Department of Homeland Security, June 2002)"; "Tomorrow is September the 12th. A milestone is passed, and a mission goes on. Be confident. Our country is strong, and our cause is even larger than our country. Ours is the cause of human dignity, freedom guided by conscience and guarded by peace. This ideal of America is the hope of all mankind" (George W. Bush, Address to the Nation on the Anniversary of the Terrorist Attacks of September 11, from Ellis Island, New York, Septemper 11, 2002). No discurso de posse do segundo mandado presidencial, George W. Bush destaca que vai terminar o seu trabalho histórico democrático: "And above all, we will finish the historic work of democracy in Afghanistan and Iraq so those nations can light the way for others and help transform a troubled part of the world. America is a nation with a mission, and that mission comes from our most basic beliefs. We have no desire to dominate, no ambitions of empire. Our aim is a democratic peace, a peace founded upon the dignity and rights of every man and woman. America acts in this cause with friends and allies at our side, yet we understand our special calling: This great Republic will lead the cause of freedom (George W. Bush, State of the Union, 2004)"; "Across the generations, we have proclaimed the imperative of self-government, because no one is fit to be a master and no one deserves to be a slave. Advancing these ideals is the mission that created our Nation. It is the honorable achievement of our fathers. Now, it is the urgent requirement of our Nation's security and the calling of our time (George W. Bush, Inaugural Address, 2005)” (Santos, 2010, p. 158-191). 
de uma forma de manter a hegemonia do pensamento europeu, o sistema de mundo não democrático e as desigualdades sociais, defendendo como um caminho contrário o universalismo universal.

Da mesma forma, Raimundo Panikkar (2004, p. 236-237) defende que a noção de direitos humanos é, sim, uma concepção ocidental, porém, ao se questionar se o mundo deveria deixar de colocá-los em prática e defendê-los, reponde que não. Isso porque na sociedade contemporânea e tecnológica os direitos humanos são fundamentais. Aliado a isso, as culturas não ocidentais precisam mostrar-se para o mundo por intermédio dos próprios valores e concepções de direitos que são ou não correspondentes aos direitos humanos. Além disso, deve ser criado um espaço para diálogo intercultural, posto que o diálogo é um meio para se criarem consensos para a vida em sociedade. Nos dizeres de José Manuel Pureza (2004, p. 98), "é no consenso intersubjectivo resultante de uma argumentação racional que se decifra o sentido da relação complexa entre democratização (da sociedade internacional) e humanização (do Direito Internacional)”.

No sentido oposto, Otfried Höffe (2000, p. 83) sustenta a posição de que os direitos humanos não se constituem uma instituição especificamente europeia, haja vista que a ideia de igualdade dos seres humanos remonta em muitos mitos conhecidos sobre a criação do mundo. $\mathrm{O}$ autor pergunta-se sobre onde estaria o "moderno" dos direitos humanos, pois o que os difere do período anterior à Declaração Universal é que nessa época não possuíam consequências jurídicas.

Não se espera um consenso entre os autores, porém é de se admitir que as preocupações trazidas por Wallerstein expressam justamente o risco ao interpretar-se de maneira errada o que os direitos humanos realmente buscam proteger. Nesse sentido, fazendo uma relação entre o universalismo e o relativismo cultural, no que concerne à visão do mundo ocidental, explica Flávia Piovesan (2004, p. 62) que, para os que defendem o relativismo cultural, “a pretensão de universalidade desses instrumentos 
[a autora refere-se aos instrumentos internacionais de direitos humanos] simboliza a arrogância do imperialismo cultural do mundo ocidental, que tenta universalizar suas próprias crenças”, sugerindo, por óbvio, que essa concepção universal, na realidade, é a imposição de um modelo ocidental que acaba por violar o multiculturalismo. De outro modo, os defensores do universalismo dos direitos humanos afirmam que a posição relativista “revela o esforço em justificar graves casos de violações dos direitos humanos que, a partir do sofisticado argumento do relativismo cultural, ficariam imunes ao controle da comunidade internacional”, ou seja, os Estados firmam instrumentos internacionais, os quais permitem um controle pela comunidade internacional dos atos que transgridam os direitos humanos, porque o respeito à dignidade humana deve ser observado na sociedade contemporânea, uma vez que o descumprimento dos Tratados merece uma punição ao Estado infrator.

Diante do multiculturalismo e da ideia do universalismo dos direitos humanos e sua promoção entre os povos, o universalismo universal proposto por Wallerstein fortalece a ideia de que as noções que hoje são defendidas na realidade promovem o pensamento europeu, não dando espaço às demais culturas. Por isso, esse universalismo é ímpar, pois, “recusa as caracterizações essencialistas da realidade social; historiza tanto o universal quanto o particular, reunifica os lados ditos científico e humanístico em uma epistemologia”, nesse caso para que o universalismo não seja domínio dos cientistas, "e permite-nos ver com olhos extremamente clínicos todas as justificativas de 'intervenção’ dos poderosos contra os fracos” (Wallerstein, 2007, p. 118).

Assim, o caminho político demanda que as escolhas tomadas pelos governantes atentem para o diálogo entre as culturas, pois, para que o universalismo universal abra seu espaço, a concepção dos direitos não pode 
ficar adstrita aos documentos internacionais firmados, principalmente pelo ocidente, muito antes, pelo contrário, deve buscar-se construir e evoluir conforme a valores que constituam a base universal das culturas.

\section{CONSIDERAÇÕES FINAIS}

Conforme restou evidenciado, é possível garantir a diversidade cultural presente no multiculturalismo enquanto se protegem os direitos humanos, tendo em vista que o que se busca é a proteção do ser humano, cabendo ao Estado e aos demais indivíduos promover políticas de reconhecimento e proteção. Há que se atentar que não existem culturas inferiores ou superiores às demais; o que existem são sistemas de crenças diversos, que necessitam de proteção e respeito. Não se pode, porém, perder uma reflexão crítica acerca das diversas culturas, de modo a analisar se determinados costumes realmente são necessários e se, de fato, fazem parte do sistema de crenças da sociedade em questão.

Apesar da visão redutora que o relativismo cultural apresenta sobre a (im) possibilidade de universalização dos direitos humanos, é importante observar que os valores que são propriamente universais não violam os direitos das demais culturas. Por meio da distinção realizada por François Jullien (2009) pode-se observar que existem valores que se constituem um dever-ser em todas as culturas, independente do código interno que possuem, afinal todas são formadas por seres humanos.

É preciso ficar atento à padronização imposta pela uniformização dos direitos humanos, tendo em vista que isso prejudica o multiculturalismo e impõe valores culturais de um povo sobre o outro. A uniformização não promove a universalização dos direitos humanos; muito antes, pelo contrário, viola os direitos humanos das demais culturas. Impor padrões 
considerados aceitáveis para culturas desenvolvidas, em detrimento de culturas consideradas subdesenvolvidas, propaga a ideia da uniformização e vai contra a política de reconhecimento dessa identidade.

Como os valores universais são indeterminados, tornou-se importante que sejam expressos no sistema normativo. A Declaração Universal dos Direitos Humanos foi um passo importante para que a proteção atingisse o plano da fundamentação desses direitos. Além dos tratados internacionais, os direitos humanos tornam-se mais fortes quando são expressos no ordenamento interno de cada estado membro. Ressalta-se, contudo, que tal previsão não é obrigatória para que sejam protegidos e respeitados, pois já são um símbolo universalmente reconhecido.

No mais, devem ser fortalecidos os diálogos interculturais; somente assim é possível colocar-se no lugar do outro, olhar através de outras janelas, para, então, promover, de fato, o universalismo dos direitos humanos. Claro que o caminho é longo, tendo em vista que o consenso é uma tarefa árdua, contudo não se pode fraquejar, pois tais direitos continuadamente são violados.

\section{REFERÊNCIAS}

BALDI, C. A. (Org.). Direitos humanos na sociedade cosmopolita. Rio de Janeiro: Renovar, 2004.

BARRETO, V. P. O fetiche dos direitos humanos e outros temas. São Paulo: Lumen Juris, 2010.

BOBBIO, N. A era dos direitos. Tradução Carlos Nelson Coutinho. Rio de Janeiro: Elsevier, 2004.

COMPARATO, F. K. A afirmação histórica dos direitos humanos. 5. ed. rev. e atual. São Paulo: Saraiva, 2007. 
DAVUTOGLU, A. Cultura global versus pluralismo cultural: hegemonia civilizacional ou diálogo e interação entre civilizações. In: BALDI, C. A. (Org.). Direitos humanos na sociedade cosmopolita. Rio de Janeiro: Renovar, 2004. p. 101-138.

DOUZINAS, C. O fim dos direitos humanos. São Leopoldo: Unisinos, 2009.

EBERHARD, C. Direitos humanos e diálogo intercultural: uma perspectiva antropológica. In: BALDI, C. A. (Org.). Direitos humanos na sociedade cosmopolita. Rio de Janeiro: Renovar, 2004. p. 159-204.

HÖFFE, O. Derecho intercultural. Tradução Rafael Sevilla. Espanha: Gedisa Editorial, 2000.

JULLIEN, F. O diálogo entre culturas: do universal ao multiculturalismo. Tradução André Telles. Rio de Janeiro: Jorge Zahar, 2009.

MARCONDES, D. Apresentação à edição brasileira. In: JULLIEN, F. O diálogo entre culturas: do universal ao multiculturalismo. Tradução André Telles. Rio de Janeiro: Jorge Zahar, 2009.

PANIKKAR, R. Seria a noção de direitos humanos um conceito ocidental? In: BALDI, C. A. (Org.). Direitos humanos na sociedade cosmopolita. Rio de Janeiro: Renovar, 2004. p. 205-238.

PIOVESAN, F.(Coord.). Direitos humanos: fundamento, proteção e implementação. Curitiba: Juruá, 2007. V. 2.

A universalidade e a indivisibilidade dos direitos humanos: desafios e perspectivas. In: BALDI, C. A. (Org.). Direitos humanos na sociedade cosmopolita. Rio de Janeiro: Renovar, 2004. p. 45-72.

PUREZA, J. M. Direito internacional e comunidade de pessoas: da indiferença aos direitos humanos. In: BALDI, C. A. (Org.). Direitos humanos na sociedade cosmopolita. Rio de Janeiro: Renovar, 2004. p. 73-100.

RACHELS, J. Os elementos da filosofia moral. Tradução Roberto Cavallari Filho. Barueri: Manole, 2006. 
SANTOS, B. S. Por uma concepção multicultural dos direitos humanos. In: BALDI, C. A. (Org.). Direitos humanos na sociedade cosmopolita. Rio de Janeiro: Renovar, 2004. p. 239-278.

SANTOS, M. H. C. Exportação de democracia na política externa norte-americana no pós-guerra-fria: doutrinas e o uso da força. Rev. Bras. Polit. Int. [on-line], v. 53, n. 1, p. 158-191, 2010.

TAYLOR, C. A política do reconhecimento. In: TAYLOR, C. et al. Multiculturalismo: examinando a política de reconhecimento. Lisboa: Instituto Piaget; Minigráfica, 1998.

WALLERSTEIN, I. M. O universalismo europeu: a retórica do poder. São Paulo: Boitempo, 2007.

Recebido em: $15 / 4 / 2014$

Aceito em: 23/12/2014 